2013s-44

\title{
Modeling Multivariate Data Revisions
}

Jan P.A.M. Jacobs, Samad Sarferaz,

Jan-Egbert Sturm, Simon van Norden

\begin{tabular}{c}
\hline Série Scientifique \\
Scientific Series
\end{tabular}

Montréal

Novembre/November 2013

(C) 2013 Jan P.A.M. Jacobs, Samad Sarferaz, Jan-Egbert Sturm, Simon van Norden. Tous droits réservés. All rights reserved. Reproduction partielle permise avec citation du document source, incluant la notice $\odot$.

Short sections may be quoted without explicit permission, if full credit, including $($ notice, is given to the source.
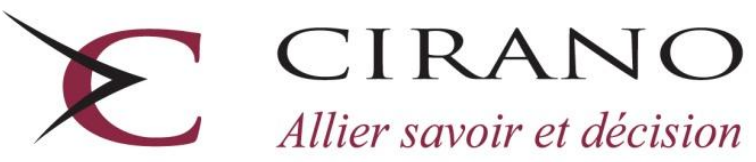

Allier savoir et décision

Centre interuniversitaire de recherche en analyse des organisations 


\section{CIRANO}

Le CIRANO est un organisme sans but lucratif constitué en vertu de la Loi des compagnies du Québec. Le financement de son infrastructure et de ses activités de recherche provient des cotisations de ses organisations-membres, d'une subvention d'infrastructure du Ministère de l'Enseignement supérieur, de la Recherche, de la Science et de la Technologie, de même que des subventions et mandats obtenus par ses équipes de recherche.

CIRANO is a private non-profit organization incorporated under the Québec Companies Act. Its infrastructure and research activities are funded through fees paid by member organizations, an infrastructure grant from the Ministère de l'Enseignement supérieur, de la Recherche, de la Science et de la Technologie, and grants and research mandates obtained by its research teams.

\section{Les partenaires du CIRANO}

\section{Partenaire majeur}

Ministère de l'Enseignement supérieur, de la Recherche, de la Science et de la Technologie

\section{Partenaires corporatifs}

Autorité des marchés financiers

Banque de développement du Canada

Banque du Canada

Banque Laurentienne du Canada

Banque Nationale du Canada

Banque Scotia

Bell Canada

BMO Groupe financier

Caisse de dépôt et placement du Québec

Fédération des caisses Desjardins du Québec

Financière Sun Life, Québec

Gaz Métro

Hydro-Québec

Industrie Canada

Investissements PSP

Ministère des Finances et de l'Économie

Power Corporation du Canada

Rio Tinto Alcan

State Street Global Advisors

Transat A.T.

Ville de Montréal

\section{Partenaires universitaires}

École Polytechnique de Montréal

École de technologie supérieure (ÉTS)

HEC Montréal

Institut national de la recherche scientifique (INRS)

McGill University

Université Concordia

Université de Montréal

Université de Sherbrooke

Université du Québec

Université du Québec à Montréal

Université Laval

Le CIRANO collabore avec de nombreux centres et chaires de recherche universitaires dont on peut consulter la liste sur son site web.

Les cahiers de la série scientifique (CS) visent à rendre accessibles des résultats de recherche effectuée au CIRANO afin de susciter échanges et commentaires. Ces cahiers sont écrits dans le style des publications scientifiques. Les idées et les opinions émises sont sous l'unique responsabilité des auteurs et ne représentent pas nécessairement les positions du CIRANO ou de ses partenaires.

This paper presents research carried out at CIRANO and aims at encouraging discussion and comment. The observations and viewpoints expressed are the sole responsibility of the authors. They do not necessarily represent positions of CIRANO or its partners. 


\title{
Modeling Multivariate Data Revisions
}

\author{
Jan P.A.M. Jacobs ${ }^{*}$, Samad Sarferaz, ${ }^{\dagger}$, \\ Jan-Egbert Sturm ${ }^{*}$, Simon van Norden ${ }^{\S}$
}

\begin{abstract}
Résumé/abstract
Data revisions in macroeconomic time series are typically studied in isolation ignoring the joint behaviour of revisions across different series. This ignores (i) the possibility that early releases of some series may help forecast revisions in other series and (ii) the problems statitical agencies may face in producing estimates consistent with accounting identities. This paper extends the Jacobs and van Norden (2011) modeling framework to multivariate data revisions. We consider systems of variables, where true values and news and noise can be correlated, and which may be linked by one or more identities. We show how to model such systems with standard linear state space models. We motivate and illustrate the multivariate modeling framework with Swiss current account data using Bayesian econometric methods for estimation and inference.
\end{abstract}

Mots clés : data revisions, state space form, linear constraints, correlated shocks, Bayesian econometrics, current account statistics, Switzerland.

Codes JEL : C22, C53, C82

\footnotetext{
${ }^{*}$ University of Groningen, University of Tasmania, CAMA and CIRANO.

KOF Swiss Economic Institute, ETH Zurich, Switzerland.

KOF Swiss Economic Institute, ETH Zurich, Switzerland and CESifo, Germany.

${ }^{\S}$ HEC Montréal, CAMA, CIRANO and CIREQ.
} 


\section{Introduction}

Data revision has become an increasingly important field of macroeconomic research in recent years, spurred in part by the creation of major databases of original release data for the US and other major OECD economies. Croushore (2011) provides a survey of the modern literature. Data revisions in individual time series are typically studied in isolation ignoring information in other related series. Zadrozny (2008), Jacobs and van Norden (2011) and Cunningham et al. (2012) are recent examples of univariate data revision models.

Many official statistics are however jointly produced by statistical agencies, calling for multivariate approaches. Such approaches should allow for

- several variables to have underlying factors for each variable (as in the Illustration shown in this paper), or a single underlying factor (as e.g. in the data reconciliation literature initiated by Stone, Champernowne and Meade (1942)) ${ }^{1}$

- the distinction of news, i.e. revisons are not forecastable, and noise, i.e. revisions are forecastable;

- new information causing simultaneous revisions in several variables;

- true values to be correlated across variables;

\footnotetext{
${ }^{1}$ Recent contributions to this area include Fixler and Nalewaik (2009) and Aruoba et al. $(2012,2013)$.
} 
- true variables of different variables to be linked via accounting identities / linear constraints.

This paper extends the Jacobs and van Norden (2011; henceforth JvN) modeling framework to systems of variables allowing for true values and news and noise measurement errors to be correlated across variables. In contrast to the multivariate approaches of Patterson (2003), who models the most recent observations from vintages rather than different vintage estimates for an observation, and Clements and Galvão (2012), who consider vintage-based VAR models that cannot deal with news or noise (Hecq and Jacobs 2009), it can incorporate all aspects listed above. Closest to our study is Kishor and Koenig (2012), who use a completely different approach. We further deviate from the existing literature on modeling multivariate data revisions by allowing for adding-up constraints and explicitly taking into account the possibility that shocks to true values, news and noise can be correlated.

We will-partly_illustrate our method with a real-time Swiss current account data set, updated from the one studied by Jacobs and Sturm (2008), and adjusted for comprehensive revisions. We estimate the parameters of our state-space model using Bayesian econometric methods, similar to those of Aruoba et al. (2012, 2013) and Schorfheide and Song (2012), and show that a multivariate model of true values outperforms univariate models of exports and imports. Implementation of correlated news and noise shocks is left for future research.

The paper is structured as follows. Section 2 briefly discusses data re- 
visions and their properties. Section 3 presents our multivariate state-space model, while Section 4 describes our Bayesian estimation methods. Section 5 illustrates our multivariate framework with Swiss current account data. Section 6 concludes.

\section{Data revisions}

Real-time data are typically displayed in the form of a data trapezoid. We move to later vintages as we move across columns from left to right and we move to later points in time when we move down the rows. Note that the frequency of vintages need not necessarily correspond to the unit of observation; for example, in our Illustration below the statistical agency publishes monthly vintages of quarterly observations. In this paper it is more convenient to work with releases, i.e. diagonals of the data trapezoid. Therefore we use the following notation in this paper: superscripts refer to releases, while subscripts refer to periods. Hence, $z_{t}^{1}$ is the first release for variable $z$ in period $t$.

Three types of data revisions can be distinguished:

1. initial revisions in the first few vintages,

2. annual (seasonal) revisions due to updated seasonal factors and the confrontation of quarterly with annual information, and 
3. historical, comprehensive or benchmark revisions, related to changes in e.g. statistical methodology.

Initial and seasonal revisions are regular and recurring, i.e. can in principle be modelled and forecast. Historical revisions are much more difficult to handle. Redefinitions like changes of base years do not cause many difficulties; however, methodological changes are much more difficult to handle. The distinction of revisions into these types requires careful handling of the real-time data and in many cases direct access to the officials of the statistical agency. Our model is intended for regular, initial revisions; in our Illustration below we adjust for the latter type of revisions. For details see Section 5.1 below.

Many official statistics are jointly produced by statistical agencies. Therefore true values, and news and noise measurement errors may be correlated across variables. Identities linking variables will also cause measurement errors to be correlated across them. To deal with revisions in more than one variable, a multivariate model is required, to which we now turn to.

\section{Our Multivariate State-Space Model}

Our multivariate state-space model follows Durbin and Koopman (2001):

$$
\begin{aligned}
& \text { measurement equation } \quad \boldsymbol{y}_{t}=\boldsymbol{Z} \boldsymbol{\alpha}_{t}+\boldsymbol{\varepsilon}_{t} \\
& \text { transition equation } \quad \boldsymbol{\alpha}_{t+1}=\boldsymbol{T} \boldsymbol{\alpha}_{t}+\boldsymbol{R} \boldsymbol{\eta}_{t}
\end{aligned}
$$


In the $\mathrm{JvN}$ framework the data vector $\boldsymbol{y}_{t}$ consists of $l$ different releases $y_{t}^{i}, i=$ $1, \ldots l$ for observation $t$. To analyse data revisions in an $N$-dimensional data vector, we stack $l$ releases of the $N$ variables (first by release then by variable) in the $N l \times 1$ data vector $\boldsymbol{y}_{t}$. So, the dimensions of the variables and error terms in the state-space form are as follows: $\boldsymbol{y}_{t}$ is $N l \times 1, \boldsymbol{\alpha}_{t}$ is $N m \times 1, \boldsymbol{\eta}_{t}$ is $N r \times 1$. Without loss of generality we include the measurement error $\varepsilon_{t}$ in the state vector and assume $\boldsymbol{\eta}_{t} \sim N\left(\mathbf{0}, \boldsymbol{I}_{N m}\right)$.

Our modeling framework is quite general and capable of handling quite complex structures. For ease of exposition, we begin with a simple state-space structure that ignores measurement errors and then show how successive features may be added to the model. Readers already quite familiar with the univariate data revision model of JvN may simply note that we stack those univariates models into a multivariate framework and skip ahead to the discussion of data reconcilation and factor structures, and correlated shocks.

\section{True values}

To help fix notation, we begin by ignoring data revision and focusing on the dynamics of our time series. In this simple case, $l=1$ so we simply have a single observed series of observations on each of our $N$ variables. In that case, $\boldsymbol{y}_{t}$ is $N \times 1 ; \boldsymbol{\alpha}_{t}=\left[\boldsymbol{y}^{\prime}, \boldsymbol{\phi}_{t}^{\prime}\right]^{\prime}$, which is $(N+N b) \times 1$, so that $\boldsymbol{\phi}_{t}$ is $N b \times 1$; and $\boldsymbol{Z}=\left[\begin{array}{ll}\boldsymbol{I}_{N} & \mathbf{0}_{N \times N b}\end{array}\right]$, which is $N \times N(b+1)$. 
The dynamics of $\boldsymbol{y}_{t}$ are uniquely determined by $\boldsymbol{\phi}_{t}$ through (2). For example, if $\phi_{t}$ is $(N \cdot k) \times 1$ and contains the first $k$ lags of each element of $\boldsymbol{y}_{t}$, then $\boldsymbol{y}_{t}$ is $\operatorname{VAR}(k+1)$. Alternatively, if $\phi_{t}$ instead contains the first $k$ lags of each element of $\boldsymbol{\eta}_{t}$, then $\boldsymbol{y}_{t}$ is a VMA $(k+1)$. Those dynamics will in turn define (2) and the $\boldsymbol{T}$ matrix; in the case of the VAR $(k+1)$ model mentioned above, $\boldsymbol{T}$ is simply our matrix of autoregressive coefficients and $\boldsymbol{R}$ determines the covariance matrix of our error terms $\boldsymbol{R} \boldsymbol{R}^{\prime}$. Suitable definition of $\phi_{t}$ allows us to model a broad range of stationary and nonstationary vector processes; Harvey (1989) provides a wide array of examples including models of trendcycle decompositions. In our Illustration below, we employ autoregressive processes $(\operatorname{AR}(2)$ and $\operatorname{VAR}(2))$ for the dynamics of the true values.

When we consider data revisions, we distinguish between "true" values of $\boldsymbol{y}_{t}$ and estimates (of various releases) published by statistical agencies. In what follows below, therefore, we will replace $\boldsymbol{y}_{t}$ in the state vector $\boldsymbol{\alpha}_{t}$ with $\widetilde{\boldsymbol{y}}_{t}$ and several other features of (1) and (2) will change. However, the role of $\phi_{t}$ will not; its only purpose is to capture the dynamics of the "true" values.

\subsection{Adding noise}

The simplest way to model data revisions is to assume that published series $\boldsymbol{y}_{t}$ consist of "true" values $\widetilde{\boldsymbol{y}}_{t}$ plus error. In this case, $l \geq 1$ and in (1) $\boldsymbol{y}_{t}$ is now $N l \times 1$, where the first $l$ rows contain the releases of the first variable from $y_{1 t}^{1}$ through $y_{1 t}^{l}$, the next $l$ rows contain $y_{2 t}^{1}$ through $y_{2 t}^{l}$, etc.; $\widetilde{\boldsymbol{y}}_{t}$ is $N \times 1 ; \phi_{t}$ remains $N b \times 1 ; \boldsymbol{\zeta}_{t}$ is $N \times l$ and contains the measurement error 
associated with each corrresponding element of $\boldsymbol{y}_{t} ; \boldsymbol{\alpha}_{t}=\left[\widetilde{\boldsymbol{y}}_{t}^{\prime}, \boldsymbol{\phi}_{t}^{\prime}, \boldsymbol{\zeta}_{t}^{\prime}\right]^{\prime}$, which is $(N+N b+N l) \times 1=N(l+b+1) \times 1 ;$ and $\boldsymbol{Z}=\left[\begin{array}{lll}\boldsymbol{I}_{N} \otimes \boldsymbol{\iota}_{l} & \mathbf{0}_{N l \times N b} & \boldsymbol{I}_{N} \otimes \boldsymbol{\iota}_{l}\end{array}\right]$, which is $N l \times N(l+b+1)$.

We may now write (2) more explicitly with

- $\boldsymbol{T}=\left[\begin{array}{cc}\boldsymbol{T}_{\phi} & \mathbf{0}_{N(b+1) \times N l} \\ \mathbf{0}_{N l \times N(b+1)} & \boldsymbol{T}_{N o i s e}\end{array}\right]$, where $\boldsymbol{T}_{\phi}$ is $N(b+1) \times N(b+1)$ and so is conformable with $\left[\widetilde{\boldsymbol{y}}^{\prime}, \boldsymbol{\phi}_{t}^{\prime}\right]^{\prime}$. Its elements are precisely those which we would have in the above case where only true values are observed. $\boldsymbol{T}_{N o i s e}$ is $N l \times N l$ and so is conformable with $\boldsymbol{\zeta}_{t} . \quad \boldsymbol{T}_{N o i s e}=\mathbf{0}_{N l \times N l}$ implies that measurement errors are independent across different calendar dates, while $\boldsymbol{T}_{\text {Noise }} \neq \mathbf{0}_{N l \times N l}$ implies that measurement errors in adjacent periods will be correlated. ${ }^{2}$

- $\boldsymbol{R}=\left[\begin{array}{cc}\boldsymbol{R}_{\phi} & \mathbf{0}_{N(b+1) \times N l} \\ \mathbf{0}_{N l \times N} & \boldsymbol{R}_{N o i s e}\end{array}\right]$ where $\boldsymbol{R}_{\phi}$ is $N(b+1) \times N(b+1)$. Its elements are precisely those which we would have in the above case where only true values are observed. $\boldsymbol{R}_{N o i s e}$ is $N l \times N l$. Its elements are precisely those which define the variance-covariance matrix of the measurement errors across releases. In the special case where measurement errors are uncorrelated across variables, this will be a block-diagonal matrix with $N$ blocks of size $l \times l$.

\footnotetext{
${ }^{2}$ In principle, we could allow for higher-order correlation in measurement errors across calendar time by stacking multiple lags of $\boldsymbol{\zeta}_{t}$ into the state vector.
} 
- $\boldsymbol{\eta}_{t}=\left[\begin{array}{ll}\widetilde{\boldsymbol{\eta}}_{t}^{\prime} & \left(\boldsymbol{\eta}_{t}^{\text {Noise }}\right)^{\prime}\end{array}\right]^{\prime}$ where $\widetilde{\boldsymbol{\eta}}$ is $N(b+1) \times 1$ and contains the time $t$ innovations to the $N$ true values of $\widetilde{\boldsymbol{y}}_{t} ; \boldsymbol{\eta}_{t}^{\text {Noise }}$ is $N l \times 1$ and contains the time $t$ innovations for all the measurement errors in $\boldsymbol{y}_{t}$.

A common source of confusion in models of data revisions is distinction between correlations across releases (or vintages) and correlations across time. If the statistical agency tends to revise its initial estimates upwards over the course of several releases, then measurement errors are correlated across releases; successive releases tend to have negative measurement errors. On the other hand, if once a year the agency incorporates information from annual income tax returns and tends to revise all the quarterly or monthly estimates for the preceding year in the same direction, then measurement errors are correlated across time. Following JvN, we define $\boldsymbol{y}_{t}$ to group all the various releases (for $1, \ldots, l$ ) for a given point in time $t$. This implies that the $\boldsymbol{R}$ matrix captures correlations across releases while the $\boldsymbol{T}$ matrix captures correlations across time.

If we think that successive revisions tend to improve the reliability of published series by tending to reduce measurement errors, we can incorporate this through further restrictions on $\boldsymbol{R}_{\text {Noise }}$. For example, in the simplest case where $\boldsymbol{R}_{N o i s e}$ is diagonal, we could require that in each of our $N$ blocks of $l$ releases, $i<j \Longleftrightarrow \sigma_{k, i}>\sigma_{k, j} \forall k$ where $\sigma_{k, n}$ is the diagonal entry in $\boldsymbol{R}_{N o i s e}$ corresponding to the $n$th release of the $k$ th variable.

The block-diagonal forms of $\boldsymbol{R}$ and $\boldsymbol{T}$ imply that measurement errors are 
independent of the true values $\widetilde{\boldsymbol{y}}_{t}$. This is sufficient to ensure that measurement errors will be noise. However, when measurement errors are news, they must be correlated with $\widetilde{\boldsymbol{y}}$, which in turn will require the introduction of some off-diagonal elements as we will see in the next section.

\subsection{Adding news}

\subsubsection{News versus noise}

The modeling of measurement errors has two main traditions. The older and most widespread approach models measurement errors as noise; i.e. random errors which are orthogonal to true values $\left(\widetilde{y}_{t}\right)$. This implies for all releases $i$ and for the $i$ th release of a single variable $y_{t}^{i}$ that

$$
y_{t}^{i}=\widetilde{y}_{t}+\zeta_{t}^{i}, \quad \operatorname{cov}\left(\widetilde{y}_{t}, \zeta_{t}^{i}\right)=0
$$

This is precisely the case we saw above. The newer tradition, motivated by Mankiw, Runkle and Shapiro (1984), Mankiw and Shapiro (1986) and de Jong (1987), describes measurement errors as news. News errors imply that published data are optimal forecasts, so revisions are orthogonal to earlier 
releases and are not forecastable. ${ }^{3}$ More precisely, we require that

$$
\widetilde{y}_{t}=y_{t}^{i}+\nu_{t}^{i}, \quad \operatorname{cov}\left(y_{t}^{i}, \nu_{t}^{i}\right)=0
$$

Of course, a direct implication of this last condition is that $\operatorname{cov}\left(\widetilde{y}_{t}, \nu_{t}^{i}\right) \neq 0$. Furthermore, if the information available to the statistical agency increases through time, the variance of the measurement errors $\nu_{t}^{i}$ must be decreasing. Since $\operatorname{var}\left(\widetilde{y}_{t}\right)$ is given, decreases in $\operatorname{var}\left(\nu_{t}^{i}\right)$ imply an offsetting increase in $\operatorname{var}\left(y_{t}^{i}\right)$. This is precisely the opposite of the noise case, where decreases in $\operatorname{var}\left(\zeta_{t}^{i}\right)$ imply a corresponding decrease in $\operatorname{var}\left(y_{t}^{i}\right) \cdot \operatorname{cov}\left(y_{t}^{i}, \nu_{t}^{i}\right)=0$ also implies that news $\nu_{t}^{i}$ will be positively correlated with innovations in $\widetilde{y}_{t}$. We accommodate this by adding off-diagonal elements to $\boldsymbol{R}$.

\subsubsection{A model of news}

If measurement errors are news rather than noise, the only change required to the "noise" state-space model that we considered above is in $\boldsymbol{R}$. However, to avoid confusion we will relabel the following elements without changing their dimensions: $\boldsymbol{T}_{\text {Noise }}$ will be renamed $\boldsymbol{T}_{\text {News }} ; \boldsymbol{\zeta}_{t}$ will be renamed $\boldsymbol{\nu}_{t}$ and

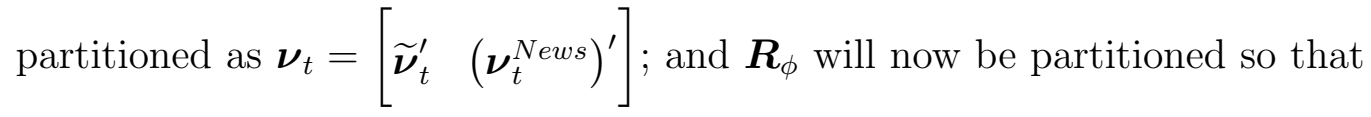

\footnotetext{
${ }^{3}$ Sargent (1989) motivates this by modeling the statistical agency as solving a meansquared error estimation problem by linearly projecting the variables they seek to estimate on the set of available information. As more information arrives, estimates become more precise. However, analogous to the case of rational expectations, data revisions will be unpredictable given the information used to construct the original estimates.
} 
$\boldsymbol{R}_{\phi}=\left[\begin{array}{ll}\boldsymbol{R}_{\phi 1}^{\prime} & \boldsymbol{R}_{\phi 2}^{\prime}\end{array}\right]^{\prime}$ with the first of its $N$ rows in $\boldsymbol{R}_{\phi 1}$ and the remaining $N b$ rows in $\boldsymbol{R}_{\phi 2}$.

Also, whereas previously $\boldsymbol{R}=\left[\begin{array}{cc}\boldsymbol{R}_{\phi} & \mathbf{0}_{N(b+1) \times N l} \\ \mathbf{0}_{N l \times N(b+1)} & \boldsymbol{R}_{N o i s e}\end{array}\right]$, we now redefine $\boldsymbol{R}$ as

$$
\boldsymbol{R}=\left[\begin{array}{cc}
\boldsymbol{R}_{\phi 1} & \boldsymbol{R}_{N e w s} \\
\boldsymbol{R}_{\phi 2} & \mathbf{0}_{N b \times N l} \\
\mathbf{0}_{N l \times N(b+1)} & -\boldsymbol{U} \cdot \operatorname{diag}\left(\vec{\sigma}_{\nu}\right)
\end{array}\right]
$$

where

- $\vec{\sigma}_{\nu} \equiv\left[\sigma_{\nu 1}, \sigma_{\nu 2}, \ldots, \sigma_{\nu N l}\right]^{\prime}$ is a $N l \times 1$ vector containing the standard deviations of news shocks for every release and every variable; the first $l$ entries contain the news shocks for releases 1 through $l$ of variable 1 , then next $l$ entries contain the news shocks for variable 2, etc.;

- $\boldsymbol{R}_{N e w s}=\left(\boldsymbol{I}_{N} \otimes \boldsymbol{\iota}_{l}^{\prime}\right) \cdot \vec{\sigma}_{\nu}$, an $N \times N l$ matrix; which is block diagonal, with $N$ blocks each consisting of a row vector of length $l$; the $j$ th block contains the standard deviation of the $l$ news shocks for variable $j$;

- $\boldsymbol{U}_{l}$ is a $l \times l$ matrix with zeros below the main diagonal and ones everywhere else;

- $\boldsymbol{U} \equiv \boldsymbol{I}_{N} \otimes \boldsymbol{U}_{l}$ is a $N l \times N l$ matrix;

- $\operatorname{diag}\left(\vec{\sigma}_{\nu}\right)$ is a $N l \times N l$ matrix with $\vec{\sigma}_{\nu}$ on its main diagonal and zeros everywhere else. 
The effect of $\boldsymbol{R}_{\text {News }}$ is that it accumulates, for each of the $N$ variables, all the $l$ different news shocks and adds them to the innovations affecting that variable's true values $\widetilde{y}_{t}^{i}$. This off-diagonal matrix thereby ensures that revisions will be correlated with innovations to true values. In contrast, $-\boldsymbol{U} \cdot \operatorname{diag}\left(\vec{\sigma}_{\nu}\right)$ then removes some or all of these innovations from the various releases, with earlier releases having more information removed. This means that there is no need to impose restrictions on the elements of $\left[\sigma_{\nu 1}, \sigma_{\nu 2}, \ldots, \sigma_{\nu N l}\right]$ in order to ensure that later releases are more precise or more volatile than earlier releases. Since later releases contain more of the shocks to true values than earlier releases, this also ensures that revisions will tend to be positively correlated with true values, as we discussed above. ${ }^{4}$

In news models, note that for each variable the number of free parameters in $\boldsymbol{R}$ grows linearly with the number of releases $l$, whereas with noise models it may grow proportional to $l^{2}$. This simply reflects the fact that the assumption of news imposes more restrictions on the behaviour of data revisions than does the assumption of noise.

\subsection{A model of news and noise}

A common empirical finding is that data revisions appear to be neither pure news nor pure noise. We therefore allow for revisions to be the sum of both

\footnotetext{
${ }^{4}$ Dungey et al. (2013b) discuss how the shock correlations imposed in the state-space representation of news shocks relate to the state-space representation of the BeveridgeNelson decomposition, while Dungey et al. (2013a) note that such shock correlations imply that the "smoothed" estimates of the true values $\widetilde{y}_{t}$ produced by usual Kalman filter recursions will be more variable than the corresponding "filtered" estimates.
} 
news and noise components. This is done by expanding the state vector to contain both types of measurement errors and conformably expanding the rest of our system matrices. Our the state vector $\boldsymbol{\alpha}_{t}$ then becomes

$$
\boldsymbol{\alpha}_{t}=\left[\tilde{\boldsymbol{y}}_{t}^{\prime}, \boldsymbol{\phi}_{t}^{\prime}, \boldsymbol{\nu}_{t}^{\prime}, \boldsymbol{\zeta}_{t}^{\prime}\right]^{\prime}
$$

where the definitions are as above and the four components are of length $N$, $\mathrm{Nb}, \mathrm{Nl}$ and $\mathrm{Nl}$ respectively. We conformably partition

$$
\boldsymbol{Z}=\left[\widetilde{\boldsymbol{Z}}, \mathbf{0}_{N l \times N b}, \boldsymbol{I}_{N l}, \boldsymbol{I}_{N l}\right]
$$

where $\widetilde{\boldsymbol{Z}}=\boldsymbol{I}_{N} \otimes \boldsymbol{\iota}_{l}$; as before, this is a $N l \times N$ block-diagonal matrix with a vector of $l$ ones on the main diagonal. The measurement equation (1) then simplifies to

$$
\boldsymbol{y}_{t}=\boldsymbol{Z} \boldsymbol{\alpha}_{t}=\tilde{\boldsymbol{y}}_{t}+\boldsymbol{\nu}_{t}+\boldsymbol{\zeta}_{t}=\text { 'Truth' + 'News' + 'Noise' }
$$

Moving on to the Transition equation, we analogously partition matrix $T$ as

$$
\boldsymbol{T}=\left[\begin{array}{ccc}
\boldsymbol{T}_{\phi} & \mathbf{0} & \mathbf{0} \\
\mathbf{0} & \boldsymbol{T}_{\text {News }} & \mathbf{0} \\
\mathbf{0} & \mathbf{0} & \boldsymbol{T}_{\text {Noise }}
\end{array}\right]
$$

where $\boldsymbol{T}_{\phi}, \boldsymbol{T}_{\text {News }}$ and $\boldsymbol{T}_{\text {Noise }}$ are as previously defined. 
$\boldsymbol{R}$ becomes a $N(1+b+2 l) \times N(1+b+2 l)$ matrix partitioned as follows

$$
\boldsymbol{R}=\left[\begin{array}{ccc}
\boldsymbol{R}_{\phi 1} & \boldsymbol{R}_{\text {News }} & \mathbf{0} \\
\boldsymbol{R}_{\phi 2} & \mathbf{0} & \mathbf{0} \\
\mathbf{0} & -\boldsymbol{U} \cdot \operatorname{diag}\left(\vec{\sigma}_{\nu}\right) & \mathbf{0} \\
\mathbf{0} & \mathbf{0} & \boldsymbol{R}_{\text {Noise }}
\end{array}\right]
$$

where $\boldsymbol{R}_{\phi 1}, \boldsymbol{R}_{\phi 2}, \boldsymbol{R}_{\text {News }}, \boldsymbol{R}_{\text {Noise }}, \boldsymbol{U}$ and $\operatorname{diag}\left(\vec{\sigma}_{\nu}\right)$ are as defined above. Finally, we partition the error vector associated with the transition equation as $\boldsymbol{\eta}_{t}=\left[\boldsymbol{\eta}_{e t}^{\prime}, \boldsymbol{\eta}_{\nu t}^{\prime}, \boldsymbol{\eta}_{\zeta t}^{\prime}\right]^{\prime}$, where $\boldsymbol{\eta}_{e t}$ (with length $1+b$ ) refers to errors associated with the true values, and $\boldsymbol{\eta}_{\nu t}$ and $\boldsymbol{\eta}_{\zeta t}$ (both of length $l$ ) are the errors for news and noise, respectively.

In our Illustration in Section 5 below we assume orthogonal news and noise shocks for the $l$ releases of the $N$ variables in the system. In future research, we will relax this assumption. Section 3.5 discusses the modeling of correlated shocks in more detail.

The transition equation assumes that news and noise terms only enter the dynamic equations for the variables to which they belong, i.e. news shocks to the first variable enter the the news equation of the first variable in the system. This is the assumption we make in the Illustration below. More complex news-noise structures are of course also possible. 


\subsection{Data reconciliation and factor structures}

All of the above models of data revision have a factor structure which relates a single underlying true value $\widetilde{y}_{i, t}$ to a vector of $l$ different releases. Conventional factor models identify the underlying factors by assuming that deviations from the factor are orthogonal to the factor itself. This maximizes the explanatory power of the underlying factor and also exactly corresponds to the properties of our "noise" errors. "News" errors represent an alternative formulation of the factor structure related to Beveridge-Nelson decompositions. $^{5}$ In both cases we have thus far assumed that we have as many underlying true values (i.e. factors) as we have distinct series. However, the framework may also be easily adapted to cases whether this is no longer true.

Economists are sometimes faced with the problem of reconciling conflicting official estimates. For example, current and capital account balances should add to zero, but measurement problems commonly result in important differences. Some countries (including the USA) publish distinct estimates of Gross Domestic Product and Gross Domestic Income. Conceptually these should be identical, but recent work has highlighted some important differences. ${ }^{6}$ Other examples include reconciling estimates produced from different methodologies, such as those produced by surveys and censuses, or plant-level and firm-level surveys, or household and establishment surveys. These are situations in which we have fewer underlying true values than we

\footnotetext{
${ }^{5}$ See Dungey et al. (2013b).

${ }^{6}$ See e.g. Fixler and Nalewaik (2009) and Aruoba et al. (2012, 2013).
} 
have reported series. Co-integration is another example where the number of factors, in this case common stochastic trends, is less than the number of series.

More generally, we can think of having $N$ elements in $\widetilde{\boldsymbol{y}}_{t}$, but that economic theory implies a set of linear restrictions on those values such that

$$
\boldsymbol{W} \cdot \tilde{\boldsymbol{y}}_{t}=\boldsymbol{w}
$$

Such restrictions can easily be incorported in standard state-space systems by augmenting the measurement equation (1) to give

$$
\left[\begin{array}{l}
\boldsymbol{y}_{t} \\
\boldsymbol{w}
\end{array}\right]=\left[\begin{array}{c}
\boldsymbol{Z} \\
\boldsymbol{W}
\end{array}\right] \tilde{\boldsymbol{y}}_{t}
$$

This formulation preserves $\tilde{\boldsymbol{y}}$ as a full $N$-dimension vector which is now subject to a number of linear constraints. In simple cases, an alternative formulation would be to reduce the dimension of $\tilde{\boldsymbol{y}}$ and directly incorporate the factor restrictions in the specification of $\boldsymbol{Z}$. For example, consider the case where the last $p$ of our $N$ variables are simply alternative measures of the same underlying economic concept. In that case, when we construct our $\boldsymbol{Z}=\left[\widetilde{\boldsymbol{Z}}, \mathbf{0}_{N l \times N b}, \boldsymbol{I}_{N l}, \boldsymbol{I}_{N l}\right]$, we can replace $\widetilde{\boldsymbol{Z}}=\boldsymbol{I}_{N} \otimes \boldsymbol{\iota}_{l}$ with $\widetilde{\boldsymbol{Z}^{*}} \equiv\left[\begin{array}{cc}\boldsymbol{I}_{N-p} \otimes \boldsymbol{\iota}_{l} & \mathbf{0}_{l(N-p) \times 1} \\ \mathbf{0}_{p l \times(N-p)} & \boldsymbol{\iota}_{p l}\end{array}\right]$. This causes all $l$ releases of the last $p$ variables 
to share the same true values. ${ }^{7}$ Obviously, this also reduces the dimension of $\tilde{\boldsymbol{y}}_{t}$ from $N$ to $N-p+1$, and may (or may not) reduce the dimension of $\phi_{t}$. However, this need not reduce the dimensions of $\boldsymbol{\nu}_{t}^{\prime}$ or $\boldsymbol{\zeta}$, as the measurement errors affecting each variable will typically continue to be unique to that series.

Note that in such a system, the news shocks of several variables are all shared by a single element of $\tilde{\boldsymbol{y}}_{t}$. To the extent that innovations in different published series are correlated, this means that news shocks must be correlated across variables, a possibility that we have not previously considered. We discuss the modeling of such systems of correlated shocks in the next section.

\subsection{Correlated shocks}

Correlated shocks to true values, news or noise change the variance-covariance of the innovations $\boldsymbol{R} \boldsymbol{\eta}$ in the state equation. We can model this in two ways: (i) taking aboard the correlation in matrix $\boldsymbol{R}$ to get $\boldsymbol{R}^{+}$, without changing the properties of the shocks, i.e. $\boldsymbol{\eta}_{t} \sim N\left(\mathbf{0}, \boldsymbol{I}_{N m}\right)$; or (ii) keeping the same matrix $\boldsymbol{R}$ and allowing for correlation between the elements of $\boldsymbol{\eta}$ through a general variance-covariance matrix $\boldsymbol{Q}$, i.e. $\boldsymbol{\eta}_{t}^{+} \sim N(\mathbf{0}, \boldsymbol{Q})$. In both cases the variance-covariance matrix of the innovations becomes $\boldsymbol{\Omega}^{+}$, i.e. $\mathrm{E}\left(\boldsymbol{R}^{+} \boldsymbol{\eta} \boldsymbol{\eta}^{\prime}\left(\boldsymbol{R}^{+}\right)^{\prime}\right)=\mathrm{E}\left(\boldsymbol{R} \boldsymbol{\eta}^{+}\left(\boldsymbol{\eta}^{+}\right)^{\prime} \boldsymbol{R}^{\prime}\right)=\boldsymbol{\Omega}^{+}$, which makes the specifications

\footnotetext{
${ }^{7} \mathrm{~A}$ simple extension would the case were we assume that all $p$ variables are the same up to a $p \times 1$ vector of scaling factors $\vec{\lambda}$. In that case, we need only replace $\boldsymbol{\iota}_{p l}$ with $\vec{\lambda} \otimes \boldsymbol{\iota}_{l}$.
} 
observationally equivalent. In our Illustration below, we apply the second method to deal with correlated shocks in our implementation of our VAR system of true values.

We now describe how to incorporate news shocks that are correlated across variables in the matrix $\boldsymbol{R}^{+}$. More formally, let $H_{\tau}^{j} \equiv\left\{y_{j t}^{\tau}, y_{j t}^{\tau-1}, y_{j t}^{\tau-2}, \ldots\right\}$ be the set of all current and past releases of some scalar time series $y_{j t}$ and let $H_{\tau}^{\boldsymbol{y}} \equiv\left\{\boldsymbol{y}_{t}^{\tau}, \boldsymbol{y}_{t}^{\tau-1}, \boldsymbol{y}_{t}^{\tau-2}, \ldots\right\}$ be the set of all current and past releases of some vector time series $\boldsymbol{y}$ whose $j$ th element is $y_{j t}$. In this context, we may define "news" in two different ways. We refer to measurement errors as Univariate News if and only if, for some series $j$, current and past estimates of the series do not help us predict its future revisions. Mathematically, we may write this as $E\left(y_{j t}^{\tau+i}-y_{j t}^{\tau} \mid H_{\tau}^{j}\right)=0 \forall t, \tau, j$ and $\forall i>0$. This is the definition used above in Section 3.2. A more restrictive case will be called Multivariate News: in this case the revisions of series $j$ cannot be predicted by current or past estimates of any of the series in $\boldsymbol{y}_{t}$. We may define this more formally as the case where $E\left(y_{j t}^{\tau+i}-y_{j t}^{\tau} \mid H_{\tau}^{\boldsymbol{y}}\right)=0 \forall t, \tau, j$ and $\forall i>0$.

Note that

- the only difference between Univariate and Multivariate News is the information set on which we condition the expectations.

- $H_{\tau}^{j} \subset H_{\tau}^{\boldsymbol{y}}$. Therefore, if the Multivariate News condition is satisfied, the Univariate News condition will also be satisfied. 
- with Multivariate News, news shocks may only be correlated across variables if they are both shocks to the same release $\tau$.

We now consider the problem of incorporating Multivariate News into our model. In Section 3.3 above, we specified the final term in the state equation to have the form

$$
\left[\begin{array}{ccc}
\boldsymbol{R}_{\phi 1} & \boldsymbol{R}_{\text {News }} & \mathbf{0} \\
\boldsymbol{R}_{\phi 2} & \mathbf{0} & \mathbf{0} \\
0 & -\boldsymbol{U} \cdot \operatorname{diag}\left(\vec{\sigma}_{\nu}\right) & \mathbf{0} \\
\mathbf{0} & \mathbf{0} & \boldsymbol{R}_{N o i s e}
\end{array}\right] \cdot\left[\begin{array}{c}
\boldsymbol{\eta}_{e t} \\
\boldsymbol{\eta}_{\nu t} \\
\boldsymbol{\eta}_{\zeta t}
\end{array}\right]
$$

Correlated news requires only that we modify the columns of $\boldsymbol{R}$ corresponding to $\boldsymbol{\eta}_{\nu t}$. This can be done as follows:

- $\boldsymbol{\lambda}_{i j} \equiv$ a row vector of length $l$ which captures the comovements of innovations to the estimates of variable $j$ and variable $i$. This is a $1 \times l$ vector since the comovement may vary across the $l$ different releases of the series.

- $\operatorname{diag}\left(\boldsymbol{\lambda}_{i j}\right) \equiv$ a $l \times l$ matrix with the elements of $\boldsymbol{\lambda}_{i j}$ on its diagonal.

- $\boldsymbol{R}_{\text {News }}=\left[\begin{array}{ccc}\boldsymbol{\lambda}_{11} & \ldots & \boldsymbol{\lambda}_{1 N} \\ \vdots & \ddots & \vdots \\ \boldsymbol{\lambda}_{N 1} & \ldots & \boldsymbol{\lambda}_{N N}\end{array}\right]$, a $N \times N l$ matrix. 


$$
\text { - } \boldsymbol{U}_{\text {News }}=\left[\begin{array}{cccc}
-\boldsymbol{U}_{l} \cdot \operatorname{diag}\left(\boldsymbol{\lambda}_{11}\right) & \ldots & \ldots & -\boldsymbol{U}_{l} \cdot \operatorname{diag}\left(\boldsymbol{\lambda}_{1 N}\right) \\
\boldsymbol{0}_{l \times l} & \ddots & \ddots & \vdots \\
\vdots & \ddots & \ddots & \vdots \\
\boldsymbol{0}_{l \times l} & \ldots & \mathbf{0}_{l \times l} & -\boldsymbol{U}_{l} \cdot \operatorname{diag}\left(\boldsymbol{\lambda}_{N N}\right)
\end{array}\right] \text { where } \boldsymbol{U}_{l} \text { is }
$$

an $l \times l$ upper-triangular matrix of ones (as above).

In future research we will implement this $\boldsymbol{R}^{+}$matrix to model correlated news.

\section{Bayesian estimation}

To estimate the model we use standard Gibbs sampling methods (Geman and Geman 1984; Gelfand and Smith 1990; Kim and Nelson 1999). The Gibbs sampler applied in this paper proceeds as follows. Let $\boldsymbol{\Psi}$ contain all parameters of the model and $\boldsymbol{U}$ all latent variables. Given arbitrary initial values $\boldsymbol{\Psi}^{0}$ and $\boldsymbol{U}^{0}$, draws for $\boldsymbol{\Psi}$ and $\boldsymbol{U}$ are obtained from the following conditional distributions $\left\{\boldsymbol{\Psi}^{1} \sim p\left(\boldsymbol{\Psi} \mid \boldsymbol{U}^{0}\right), \boldsymbol{U}^{1} \sim p\left(\boldsymbol{U} \mid \boldsymbol{\Psi}^{1}\right)\right\},\left\{\boldsymbol{\Psi}^{2} \sim p\left(\boldsymbol{\Psi} \mid \boldsymbol{U}^{1}\right), \boldsymbol{U}^{2} \sim\right.$ $\left.p\left(\boldsymbol{U} \mid \boldsymbol{\Psi}^{2}\right)\right\}, \ldots,\left\{\boldsymbol{\Psi}^{w} \sim p\left(\boldsymbol{\Psi} \mid \boldsymbol{U}^{w-1}\right), \boldsymbol{U}^{w} \sim p\left(\boldsymbol{U} \mid \boldsymbol{\Psi}^{w}\right)\right\}$. It can be shown that under mild conditions the resulting Gibbs sequence $\left\{\boldsymbol{\Psi}^{w}, \boldsymbol{U}^{w}\right\}$ converges (in distribution) to the true joint density at a geometric rate in $w$ (Geman and Geman 1984). To obtain draws for the latent state variables in $\boldsymbol{U}$ the approach of Carter and Kohn (1994) is applied (see Kim and Nelson 1999). The parameters in $\boldsymbol{\Psi}$ are drawn from a multivariate normal distribution and an inverted Wishart distribution. 
We cycled through 100,000 Gibbs iterations, discarding the first 80,000 draws as burn-in and saving every 10th draw. Convergence was checked using recursive mean plots of the parameters.

\section{Priors}

We begin with the multivariate normally distributed prior for the parameter matrix $\boldsymbol{T}$ :

$$
\boldsymbol{T}_{\text {prior }} \sim N\left(\overline{\boldsymbol{T}}, \overline{\boldsymbol{V}}_{T}\right)
$$

For the mean of the parameters we assume that $\overline{\boldsymbol{T}}$ is an $N^{* 2} q$ vector of zeros, with $N^{*} \equiv N+N b+2 N l$ and that the variance covariance matrix $\overline{\boldsymbol{V}}_{T}$ is $N^{* 2} q \times N^{* 2} q$ identity matrix times $\tau$. For the coefficients where zero restrictions are imposed we choose $\tau$ to be close to zero. For the VAR coefficients of the true values of imports and exports we choose $\tau=10$ for all the other AR coefficients we choose $\tau=1$.

The second group of parameters of our state-space form are the parameters in the $\boldsymbol{R}$ matrix of the state equation, which enter the model in the form of the variance-covariance matrix $\mathrm{E}\left(\boldsymbol{R} \boldsymbol{\eta}^{+}\left(\boldsymbol{\eta}^{+}\right)^{\prime} \boldsymbol{R}^{\prime}\right)=\boldsymbol{\Omega}^{+}$. Rewriting $\boldsymbol{R} \boldsymbol{\eta}^{+}$by putting all parameters in the shocks allows us to draw from the distributions of the shocks. The prior on the variance covariance matrix of the shocks in the state equation follows an inverted Wishart distribution and can be expressed as:

$$
\boldsymbol{Q}_{\text {prior }} \sim I W(\overline{\boldsymbol{Q}}, \delta)
$$


where $\delta \equiv \operatorname{dim}(\boldsymbol{T})+2$ and

$$
\overline{\boldsymbol{Q}}=\left[\begin{array}{cc}
\overline{\boldsymbol{Q}}_{x y} & \mathbf{0} \\
\mathbf{0} & \boldsymbol{I}_{N^{*}-N}
\end{array}\right],
$$

where $\overline{\boldsymbol{Q}}_{x y}$ is a $2 \times 2$ matrix for the prior of the variance-covariance of errors of the true values, which is an identity matrix in case of an AR model and has ones on the diagonal and 0.9 as off-diagonal elements for the VAR of true values.

\section{Illustration}

We illustrate our multivariate data revision modeling framework with Swiss current account data. After a description of the data, we present properties of data revisions of Swiss imports, exports and the current account, and evidence of multivariate relationships. We then estimate two alternative specifications of the model, one assuming $\operatorname{AR}(2)$ processes for the true values of imports and exports whereas the other one assumes a $\operatorname{VAR}(2)$ system for the dynamics of their true values.

\subsection{Data and data properties}

In Switzerland current account figures are collected by the Swiss National Bank (SNB) and published in its Monthly Bulletins ('Statistische Monats- 
hefte'). Current account information is provided for income (exports), expenditures (imports) and net exports (exports minus imports).

Our real-time data set consists of monthly vintages with quarterly data of these three series. The first vintage, published in August 1995, covers the 1984Q1-1995Q2 period, while our last vintage, published in September 2012, has data for the 1984Q1-2012Q1 period. Hence, the publication lag is a bit over one quarter. The data are kindly provided by the Swiss National Bank (SNB).

We observe comprehensive revisions in the vintages published in August 2004, July 2005, July 2007, July 2008, December 2008. The first two can be explained by the introduction of SNA93 and ESA95. In all five cases, the SNB revised the data backward completely, i.e. back to 1984Q1. In order to mitigate the effects of these comprehensive revisions, most authors would use growth rates (Croushore 2006). However, as shown by Siklos (2008) and Knetsch and Reimers (2009), this solution is not optimal as comprehensive revisions behave differently from other revisions. Therefore, we use levels in this paper and deal with these comprehensive revisions more directly.

Unlike regular revisions, comprehensive revisions affect the vintage from the beginning to the end. As described by Jacobs and Sturm (2008) revisions in Swiss current account data mostly end after a few years and the limited subsequent revisions can be treated as occasional white noise. To eliminate the five comprehensive revisions, we extrapolate the revisions of the older 
data (back to 1984) to cover the last few years. ${ }^{8}$ For this an AR(4) process is assumed. The part not explained by this extrapolated $\mathrm{AR}(4)$ process is treated as non-comprehensive revisions.

\section{Descriptive statistics}

Although once corrected for benchmark revisions we do sometimes observe some minor revisions in our data after a time horizon of three years, these are quite rare and - as described by Jacobs and Sturm (2008) - can be treated as occasional white noise. For practical purposes, we therefore distinguish between revisions after 3,12 and 36 months. Table 1 shows that the first revisions on both the export and import side of the Swiss current account are relatively small, but tend to accumulate over time. Both expenditures (imports) and income (exports) are revised upwards on average. With a cumulative average revision of, respectively 4.2 and 2.6 percent, after three years, these are not benign for the evaluation of economic conditions in a small open economy as Switzerland. Except for the first revision the means reported in Table 1 all differ significantly from zero at the one percent level (not shown).

\section{News-noise tests, and correlation across time}

To test whether revisions reduce noise the Mincer-Zarnowitz (1969) test can be used, which regresses the revision $y_{t}^{j}-y_{t}^{1}$ on a constant and a more recent

\footnotetext{
${ }^{8}$ The observed revision patterns are as such that we extrapolate the last 18, 9, 9, 13 and 10 quarters, respectively, in these five cases.
} 
Table 1: Descriptive statistics of the revision process

Mean $\% \Delta$ to 1 st rel. Std.Dev. Min Max

\begin{tabular}{|c|c|c|c|c|c|}
\hline \multirow[b]{2}{*}{ First release } & \multicolumn{5}{|c|}{ Expenditures (imports) } \\
\hline & $62,364.61$ & & $19,689.18$ & 36,512 & 106,551 \\
\hline Revisions after 1 quarter & 452.75 & $0.7 \%$ & $1,056.56$ & $-1,099$ & 3,250 \\
\hline Revisions after 1 year & $1,740.98$ & $2.8 \%$ & $2,770.74$ & $-3,480$ & 11,510 \\
\hline \multirow[t]{2}{*}{ Revisions after 3 years } & $2,609.72$ & $4.2 \%$ & $3,418.27$ & $-3,372$ & 12,385 \\
\hline & \multicolumn{5}{|c|}{ Income (exports) } \\
\hline First release & $74,282.11$ & & $23,105.00$ & 42,881 & 121,229 \\
\hline Revisions after 1 quarter & 624.00 & $0.8 \%$ & $1,416.46$ & $-1,481$ & 4,761 \\
\hline Revisions after 1 year & $1,325.42$ & $1.8 \%$ & $3,488.96$ & $-10,052$ & 10,344 \\
\hline Revisions after 3 years & $1,959.68$ & $2.6 \%$ & $4,485.94$ & $-11,198$ & 10,511 \\
\hline
\end{tabular}

Notes: Results are based upon 57 observations. Levels and revisions are shown in millions of CHF.

release denoted with $y_{t}^{j}$, where $j=3,12,36$ months, taken as measure of the unobserved true value $\widetilde{y}_{t}$. More generally, we can write

$$
y_{t}^{j}-y_{t}^{1}=\alpha_{1}+\beta_{1} y_{t}^{j}+\zeta_{t}
$$

The null hypothesis that measurement errors are independent of true values $\left(\alpha_{1}=0, \beta_{1}=0\right)$ may be tested with a Wald test; since the errors may suffer from heteroskedasticity and autocorrelation, robust standard errors are typically used.

The analogous test of the "news" model regresses the revision $\left(y_{t}^{j}-y_{t}^{1}\right)$ 
on a constant and the first release

$$
y_{t}^{j}-y_{t}^{1}=\alpha_{2}+\beta_{2} y_{t}^{1}+\nu_{t}
$$

The similar null hypothesis $\left(\alpha_{2}=0, \beta_{2}=0\right)$ now tests whether data revisions are predictable. The two null hypotheses are mutually exclusive but they are not collectively exhaustive, i.e. we may be able to reject both hypotheses (see Aruoba, 2008, Appendix A.2).

Table 2 uses Equations (12) and (13) to test the different revision horizons of the income (exports) and expenditures (imports) sides of the current account. At the $5 \%$ level, we find evidence of a significant bias for both exports and imports at all revision horizons. Hence, both the news and noise assumptions are rejected.

The final row of Table 2 shows that the residuals of the import and export equations exhibit a substantial degree of correlation implying that an upward revision in exports goes hand in hand with an upward revision in imports. To use this information, Table 3 reports p-values of exclusion tests when estimating the two equations as a system, i.e. applying Seemingly Unrelated Regression (SUR) estimation. This strengthens our previous finding in the sense that the reported biases become more significant. At the $1 \%$ level the joint null of no bias in the news or noise specification is rejected for all types of revisions. 
Table 2: Revisions in Swiss exports and imports: 'news', 'noise' and biasOLS estimates

\begin{tabular}{|c|c|c|c|c|c|c|c|}
\hline & \multicolumn{3}{|c|}{ News } & \multicolumn{3}{|c|}{ Noise } \\
\hline & & 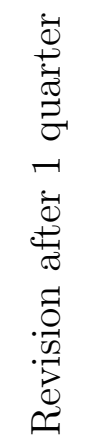 & 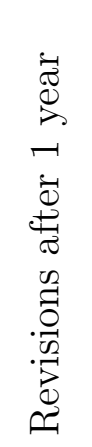 & 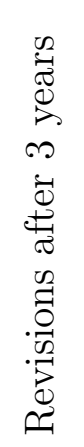 & 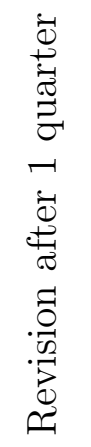 & 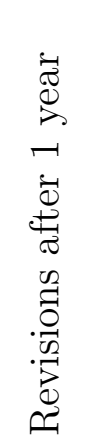 & 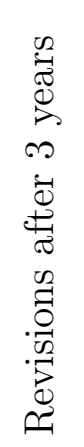 \\
\hline \multirow{8}{*}{ 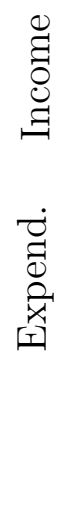 } & $\alpha=0$ & 0.26 & 0.13 & 0.03 & 0.09 & 0.59 & 0.24 \\
\hline & $\beta=0$ & 0.04 & 0.46 & 0.17 & 0.01 & 0.91 & 0.66 \\
\hline & $\alpha=\beta=0$ & 0.00 & 0.02 & 0.01 & 0.00 & 0.03 & 0.01 \\
\hline & $\alpha=0$ & 0.00 & 0.06 & 0.51 & 0.00 & 0.01 & 0.08 \\
\hline & $\beta=0$ & 0.00 & 0.00 & 0.02 & 0.00 & 0.00 & 0.00 \\
\hline & $\alpha=\beta=0$ & 0.00 & 0.00 & 0.00 & 0.00 & 0.00 & 0.00 \\
\hline & \#Obs. & 57 & 57 & 57 & 57 & 57 & 57 \\
\hline & Correl & 0.50 & 0.40 & 0.57 & 0.48 & 0.40 & 0.58 \\
\hline
\end{tabular}

Notes: Except for the rows 'Obs.' and 'Correl', this table reports p-values of exclusion tests. The results are based upon Ordinary Least Squares (OLS) regressions with NeweyWest standard errors correcting for autocorrelation up to the fourth order. 'Correl' shows the correlation between the OLS residuals of the income (exports) and expenditures (imports) equations. 
Table 3: Revisions in Swiss exports and imports: 'news', 'noise' and biasSUR estimates

\begin{tabular}{|c|c|c|c|}
\hline \multicolumn{3}{|c|}{ News } & Noise \\
\hline$\stackrel{\check{\varpi}}{\mathscr{D}}$ & 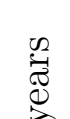 & 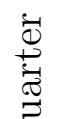 & $\dot{\varpi}$ \\
\hline- & $\infty$ & E & $\rightarrow$ \\
\hline$\ddot{\Phi}$ & $\ddot{\bar{D}}$ & 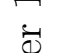 & $\dot{\bar{D}}$ \\
\hline డ & 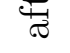 & $\stackrel{ \pm}{ \pm}$ & $\stackrel{ \pm}{\sigma}$ \\
\hline 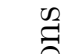 & $\stackrel{2}{\approx}$ & $\approx$ & $\stackrel{\text { a }}{\approx}$ \\
\hline 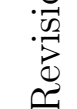 & $\frac{\sqrt[\vec{n}]{2}}{\sqrt[D]{2}}$ & $\cdot \frac{\sqrt[n]{0}}{3}$ & $\cdot \frac{\vec{n}}{\sqrt{2}}$ \\
\hline
\end{tabular}

\begin{tabular}{|c|c|c|c|c|c|c|c|}
\hline $\mathscr{g}$ & $\alpha=0$ & 0.24 & 0.07 & 0.00 & 0.13 & 0.77 & 0.26 \\
\hline & $\beta=0$ & 0.02 & 0.29 & 0.02 & 0.01 & 0.60 & 0.83 \\
\hline & $\alpha=\beta=0$ & 0.00 & 0.01 & 0.00 & 0.00 & 0.01 & 0.00 \\
\hline & $\alpha=0$ & 0.05 & 0.08 & 0.41 & 0.04 & 0.00 & 0.01 \\
\hline & $\beta=0$ & 0.00 & 0.00 & 0.01 & 0.00 & 0.00 & 0.00 \\
\hline & $\alpha=\beta=0$ & 0.00 & 0.00 & 0.00 & 0.00 & 0.00 & 0.00 \\
\hline
\end{tabular}

Notes: This table reports p-values of exclusion tests. The results are based upon Seemingly Unrelated Regressions (SUR).

Breusch-Godfrey serial correlation test outcomes in Table 4 indicate the existence of measurement errors that are correlated across time up to one lag in revisions in exports and imports, except for revisions after one quarter. 
Table 4: Revisions in Swiss exports and imports: correlation across time

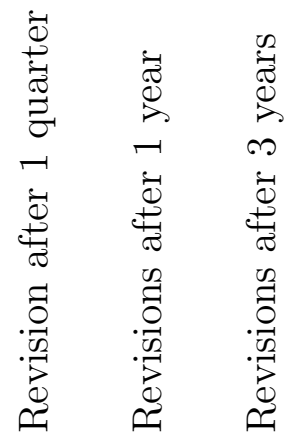

\begin{tabular}{|c|c|c|c|c|}
\hline \multirow{3}{*}{ 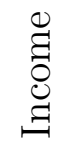 } & 1 quarter lag & 0.21 & 0.00 & 0.00 \\
\hline & 4 quarters lag & 0.11 & 0.01 & 0.00 \\
\hline & 12 quarters lag & 0.38 & 0.05 & 0.01 \\
\hline & 1 quarter lag & 0.34 & 0.01 & 0.00 \\
\hline & 4 quarters lag & 0.22 & 0.15 & 0.02 \\
\hline 承 & 12 quarters lag & 0.12 & 0.26 & 0.03 \\
\hline
\end{tabular}

Notes: This table reports p-values of Breusch-Godfrey tests for serial correlation. The allowed order of serial correlation is varied between 1, 4 and 12 lags, i.e. quarters. The results are based upon OLS. The sample is held constant, i.e. consists of 57 observations.

\subsection{Estimation of our state-space models}

In line with the above news and noise regressions, we use three releases, the 1st, the 12th and the 36th release in our estimations. By this we capture the effects of initial and annual (seasonal) revisions. The series run from 1995Q2-2009Q2, so we have 57 observations. Observed series are normalised globally, i.e. a scalar mean is subtracted and all series are scaled by the same standard deviation. By this, a constant term can be dropped from the state- 
space form. We set up the system assuming correlation across time in news and noise, i.e. diagonal matrices $\boldsymbol{T}_{3}$ and $\boldsymbol{T}_{4}$ enter the transition equation. The impact of these correlation of measurement errors across time is tested below by calculating marginal likelihoods.

Under the assumption that the true values of imports and exports follow a $\operatorname{VAR}(2)$ process

$$
\left[\begin{array}{c}
\widetilde{x}_{t} \\
\widetilde{y}_{t}
\end{array}\right]=\boldsymbol{\Theta}_{1}\left[\begin{array}{l}
\widetilde{x}_{t-1} \\
\widetilde{y}_{t-1}
\end{array}\right]+\boldsymbol{\Theta}_{2}\left[\begin{array}{l}
\widetilde{x}_{t-2} \\
\widetilde{y}_{t-2}
\end{array}\right]+\left[\begin{array}{l}
\eta_{x e t} \\
\eta_{\text {yet }}
\end{array}\right],
$$

the multivariate data revision model with news, noise, and correlated measurement errors across time can be expressed as the measurement equation

$$
\left[\begin{array}{c}
x_{t}^{1} \\
x_{t}^{2} \\
x_{t}^{3} \\
y_{t}^{1} \\
y_{t}^{2} \\
y_{t}^{3}
\end{array}\right]=\left[\begin{array}{cccccccc}
\boldsymbol{\iota}_{3} & \mathbf{0}_{3 \times 1} & \mathbf{0}_{3 \times 1} & \mathbf{0}_{3 \times 1} & \boldsymbol{I}_{3} & \mathbf{0}_{3 \times 3} & \boldsymbol{I}_{3} & \mathbf{0}_{3 \times 3} \\
\mathbf{0}_{3 \times 1} & \boldsymbol{\iota}_{3} & \mathbf{0}_{3 \times 1} & \mathbf{0}_{3 \times 1} & \mathbf{0}_{3 \times 3} & \boldsymbol{I}_{3} & \mathbf{0}_{3 \times 3} & \boldsymbol{I}_{3}
\end{array}\right]\left[\begin{array}{c}
\widetilde{x}_{t} \\
\widetilde{y}_{t} \\
\widetilde{x}_{t-1} \\
\widetilde{y}_{t-1} \\
\boldsymbol{\nu}_{t} \\
\boldsymbol{\zeta}_{t}
\end{array}\right] \text {, }
$$


and the transition equation

$$
\left[\begin{array}{c}
\widetilde{x}_{t} \\
\widetilde{y}_{t} \\
\widetilde{x}_{t-1} \\
\widetilde{y}_{t-1} \\
\boldsymbol{\nu}_{t} \\
\boldsymbol{\zeta}_{t}
\end{array}\right]=\left[\begin{array}{cccc}
\boldsymbol{\Theta}_{1} & \boldsymbol{\Theta}_{2} & \mathbf{0}_{2 \times 6} & \mathbf{0}_{2 \times 6} \\
\boldsymbol{I}_{2} & \mathbf{0}_{2 \times 2} & \mathbf{0}_{2 \times 6} & \mathbf{0}_{2 \times 6} \\
\mathbf{0}_{6 \times 2} & \mathbf{0}_{6 \times 2} & \boldsymbol{T}_{3} & \mathbf{0}_{6 \times 6} \\
\mathbf{0}_{6 \times 2} & \mathbf{0}_{6 \times 2} & \mathbf{0}_{6 \times 6} & \boldsymbol{T}_{4}
\end{array}\right]\left[\begin{array}{c}
\widetilde{x}_{t-1} \\
\widetilde{y}_{t-1} \\
\widetilde{x}_{t-2} \\
\widetilde{y}_{t-2} \\
\boldsymbol{\nu}_{t-1} \\
\boldsymbol{\zeta}_{t-1}
\end{array}\right]+
$$

$$
\begin{gathered}
{\left[\begin{array}{cccccccccccccc}
1 & 0 & \sigma_{x \nu_{1}} & \sigma_{x \nu_{2}} & \sigma_{x \nu_{3}} & 0 & 0 & 0 & 0 & 0 & 0 & 0 & 0 & 0 \\
0 & 1 & 0 & 0 & 0 & \sigma_{y \nu_{1}} & \sigma_{y \nu_{2}} & \sigma_{y \nu_{3}} & 0 & 0 & 0 & 0 & 0 & 0 \\
0 & 0 & 0 & 0 & 0 & 0 & 0 & 0 & 0 & 0 & 0 & 0 & 0 & 0 \\
0 & 0 & 0 & 0 & 0 & 0 & 0 & 0 & 0 & 0 & 0 & 0 & 0 & 0 \\
0 & 0 & -\sigma_{x \nu_{1}} & -\sigma_{x \nu_{2}} & -\sigma_{x \nu_{3}} & 0 & 0 & 0 & 0 & 0 & 0 & 0 & 0 & 0 \\
0 & 0 & 0 & -\sigma_{x \nu_{2}} & -\sigma_{x \nu_{3}} & 0 & 0 & 0 & 0 & 0 & 0 & 0 & 0 & 0 \\
0 & 0 & 0 & 0 & -\sigma_{x \nu_{3}} & 0 & 0 & 0 & 0 & 0 & 0 & 0 & 0 & 0 \\
0 & 0 & 0 & 0 & 0 & -\sigma_{y \nu_{1}} & -\sigma_{y \nu_{2}} & -\sigma_{y \nu_{3}} & 0 & 0 & 0 & 0 & 0 & 0 \\
0 & 0 & 0 & 0 & 0 & 0 & -\sigma_{y \nu_{2}} & -\sigma_{y \nu_{3}} & 0 & 0 & 0 & 0 & 0 & 0 \\
0 & 0 & 0 & 0 & 0 & 0 & 0 & -\sigma_{y \nu_{3}} & 0 & 0 & 0 & 0 & 0 & 0 \\
0 & 0 & 0 & 0 & 0 & 0 & 0 & 0 & \sigma_{x \zeta_{1}} & 0 & 0 & 0 & 0 & 0 \\
0 & 0 & 0 & 0 & 0 & 0 & 0 & 0 & 0 & \sigma_{x \zeta_{2}} & 0 & 0 & 0 & 0 \\
0 & 0 & 0 & 0 & 0 & 0 & 0 & 0 & 0 & 0 & \sigma_{x \zeta_{3}} & 0 & 0 & 0 \\
0 & 0 & 0 & 0 & 0 & 0 & 0 & 0 & 0 & 0 & 0 & \sigma_{y \zeta_{1}} & 0 & 0 \\
0 & 0 & 0 & 0 & 0 & 0 & 0 & 0 & 0 & 0 & 0 & 0 & \sigma_{y \zeta_{2}} & 0 \\
0 & 0 & 0 & 0
\end{array}\right]} \\
\text { where }
\end{gathered}
$$


Rewriting $\boldsymbol{R} \boldsymbol{\eta}$ is convenient for working out the distributions of the errors:

$$
\boldsymbol{R} \boldsymbol{\eta}=\left[\begin{array}{cccccccccccccc}
1 & 0 & 1 & 1 & 1 & 0 & 0 & 0 & 0 & 0 & 0 & 0 & 0 & 0 \\
0 & 1 & 0 & 0 & 0 & 1 & 1 & 1 & 0 & 0 & 0 & 0 & 0 & 0 \\
0 & 0 & 0 & 0 & 0 & 0 & 0 & 0 & 0 & 0 & 0 & 0 & 0 & 0 \\
0 & 0 & 0 & 0 & 0 & 0 & 0 & 0 & 0 & 0 & 0 & 0 & 0 & 0 \\
0 & 0 & -1 & -1 & -1 & 0 & 0 & 0 & 0 & 0 & 0 & 0 & 0 & 0 \\
0 & 0 & 0 & -1 & -1 & 0 & 0 & 0 & 0 & 0 & 0 & 0 & 0 & 0 \\
0 & 0 & 0 & 0 & -1 & 0 & 0 & 0 & 0 & 0 & 0 & 0 & 0 & 0 \\
0 & 0 & 0 & 0 & 0 & -1 & -1 & -1 & 0 & 0 & 0 & 0 & 0 & 0 \\
0 & 0 & 0 & 0 & 0 & 0 & -1 & -1 & 0 & 0 & 0 & 0 & 0 & 0 \\
0 & 0 & 0 & 0 & 0 & 0 & 0 & -1 & 0 & 0 & 0 & 0 & 0 & 0 \\
0 & 0 & 0 & 0 & 0 & 0 & 0 & 0 & 1 & 0 & 0 & 0 & 0 & 0 \\
\eta_{y e t} \\
\sigma_{x \nu_{1}} \eta_{x \nu_{1} t} \\
\sigma_{x \nu_{2}} \eta_{x \nu_{2} t} \\
\sigma_{x \nu_{3}} \eta_{x \nu_{3} t} \\
\sigma_{y \nu_{1}} \eta_{y \nu_{1} t} \\
\sigma_{y \nu_{2}} \eta_{y \nu_{2} t} \\
\sigma_{y \nu_{3}} \eta_{y \nu_{3} t} \\
\sigma_{x \zeta_{1}} \eta_{x \zeta_{1} t} \\
\sigma_{x \zeta_{2}} \eta_{x \zeta_{2} t} \\
\sigma_{x \zeta_{3}} \eta_{x \zeta_{3} t} \\
\sigma_{y \zeta_{1}} \eta_{y \zeta_{1} t} \\
\sigma_{y \zeta_{2}} \eta_{y \zeta_{2} t} \\
\sigma_{y \zeta_{3}} \eta_{y \zeta_{3} t}
\end{array}\right],
$$

and the other error terms follow a multivariate normal distribution with mean zero and variance $\sigma_{i}^{2}$, where $i=x \nu_{1}, x \nu_{2}, x \nu_{3}, y \nu_{1}, y \nu_{2}, y \nu_{3}, x \zeta_{1}, x \zeta_{2}, x \zeta_{3}, y \zeta_{1}$, $y \zeta_{2}$, and $y \zeta_{3}$. 
If one assumes univariate $\operatorname{AR}(2)$ processes for the dynamics of the true values of imports and exports, the specification stays the same apart from the matrices $\boldsymbol{\Theta}_{1}$ and $\boldsymbol{\Theta}_{2}$ and the variance-covariance matrix of the errors to the true values of imports and exports which in this case will be diagonal. In other words, i.e. $\theta_{1,12}=\theta_{2,12}=\theta_{1,21}=\theta_{2,21}=\sigma_{x y}=\sigma_{y x}=0$.

\section{Results}

Table 5 lists the estimation results of the bivariate data revisions models. As usual in empirical multivariate dynamic systems, the large number of parameters are difficult to interpret. The main message of the table is to show the feasibility of our multivariate data revision framework. We succeed to get estimates with Bayesian estimations methods, even allowing for news and noise and correlation of measurement errors across time.

The one standard deviation intervals arond the mean of all $\theta \mathrm{s}$ and $\sigma \mathrm{s}$ in the AR model do not contain zeros. However, one standard deviation intervals around the mean of the additional parameters of the VAR system $\left(\theta_{1,12}, \theta_{1,21}\right.$ and $\left.\theta_{2,12}, \theta_{2,21}\right)$ do contain zeros, but n1xot the correlation between the two shocks of the true values $\sigma_{x y}$. So we conclude that the better fit of our VAR specification, as reported in Table 7 below, is due to correlation between the shocks of the true values.

Table 6 shows estimation results for $\mathrm{AR}(2)$ and $\operatorname{VAR}(2)$ models of true values of exports and imports with correlated measurement errors across time. Again one standard deviation intervals around the mean contain zeros 
Table 5: Estimation results: $\operatorname{AR}(2)$ and $\operatorname{VAR}(2)$ models for the true values

\begin{tabular}{lcccc} 
Parameter & \multicolumn{2}{c}{ AR(2) outcomes } & \multicolumn{2}{c}{ VAR(2) outcomes } \\
& Median & Std. dev. & Median & Std. dev. \\
\hline$\theta_{1,11}$ & 0.509 & 0.170 & 0.444 & 0.201 \\
$\theta_{1,12}$ & - & - & 0.047 & 0.213 \\
$\theta_{1,21}$ & - & - & 0.043 & 0.200 \\
$\theta_{1,22}$ & 0.510 & 0.172 & 0.509 & 0.193 \\
$\theta_{2,11}$ & 0.371 & 0.169 & 0.316 & 0.191 \\
$\theta_{2,12}$ & - & - & 0.017 & 0.199 \\
$\theta_{2,21}$ & - & - & 0.108 & 0.206 \\
$\theta_{2,22}$ & 0.431 & 0.171 & 0.386 & 0.200 \\
$\sigma_{x x}$ & 0.329 & 0.061 & 0.329 & 0.062 \\
$\sigma_{x y}$ & - & - & 0.273 & 0.056 \\
$\sigma_{y x}$ & - & - & 0.273 & 0.056 \\
$\sigma_{y y}$ & 0.324 & 0.058 & 0.331 & 0.062 \\
$\sigma_{x \nu_{1}}$ & 0.049 & 0.011 & 0.047 & 0.010 \\
$\sigma_{x \nu_{2}}$ & 0.048 & 0.010 & 0.047 & 0.010 \\
$\sigma_{x \nu_{3}}$ & 0.088 & 0.030 & 0.084 & 0.028 \\
$\sigma_{y \nu_{1}}$ & 0.050 & 0.011 & 0.050 & 0.011 \\
$\sigma_{y \nu_{2}}$ & 0.049 & 0.011 & 0.050 & 0.011 \\
$\sigma_{y \nu_{3}}$ & 0.088 & 0.031 & 0.081 & 0.027 \\
$\sigma_{x \zeta_{1}}$ & 0.049 & 0.011 & 0.047 & 0.010 \\
$\sigma_{x \zeta_{2}}$ & 0.041 & 0.009 & 0.041 & 0.008 \\
$\sigma_{x \zeta_{3}}$ & 0.047 & 0.010 & 0.047 & 0.010 \\
$\sigma_{y \zeta_{1}}$ & 0.049 & 0.011 & 0.046 & 0.010 \\
$\sigma_{y \zeta_{2}}$ & 0.043 & 0.009 & 0.042 & 0.009 \\
$\sigma_{y \zeta_{3}}$ & 0.049 & 0.011 & 0.048 & 0.010 \\
\hline & & & &
\end{tabular}

for the parameters corresponding to the own lags in the AR and VAR models of true values, the standard deviations of shocks to the true values of imports and exports, and the correlation between those two shocks in the VAR system, and the news and noise shocks. In addition, there is some evidence of news being correlated across time, since median estimates of news to the first releases of imports and exports $\left(\boldsymbol{T}_{3,11}\right.$ and $\left.\boldsymbol{T}_{4,11}\right)$ are larger than their 
standard deviations.

Table 6: Estimation results: $\operatorname{AR}(2)$ and $\operatorname{VAR}(2)$ models for the true values with correlated measurement errors across time

\begin{tabular}{|c|c|c|c|c|}
\hline \multirow[t]{2}{*}{ Parameter } & \multicolumn{2}{|c|}{$\mathrm{AR}(2)$ outcomes } & \multicolumn{2}{|c|}{$\operatorname{VAR}(2)$ outcomes } \\
\hline & Median & Std. dev. & Median & Std. dev. \\
\hline$\theta_{1,11}$ & 0.597 & 0.196 & 0.597 & 0.221 \\
\hline$\theta_{1,12}$ & - & - & 0.018 & 0.219 \\
\hline$\theta_{1,21}$ & - & - & -0.004 & 0.204 \\
\hline$\theta_{1,22}$ & 0.611 & 0.190 & 0.632 & 0.208 \\
\hline$\theta_{2,11}$ & 0.297 & 0.192 & 0.185 & 0.206 \\
\hline$\theta_{2,12}$ & - & - & 0.003 & 0.203 \\
\hline$\theta_{2,21}$ & - & - & 0.137 & 0.210 \\
\hline$\theta_{2,22}$ & 0.339 & 0.189 & 0.303 & 0.217 \\
\hline$T_{3,11}$ & 0.265 & 0.157 & 0.360 & 0.152 \\
\hline$T_{3,22}$ & 0.173 & 0.157 & 0.265 & 0.153 \\
\hline$T_{3,33}$ & 0.161 & 0.183 & 0.236 & 0.180 \\
\hline$T_{3,44}$ & 0.296 & 0.153 & 0.363 & 0.139 \\
\hline$T_{3,55}$ & 0.196 & 0.160 & 0.239 & 0.149 \\
\hline$T_{3,66}$ & 0.165 & 0.181 & 0.194 & 0.182 \\
\hline$T_{4,11}$ & 0.185 & 0.216 & 0.335 & 0.224 \\
\hline$T_{4,22}$ & 0.123 & 0.215 & 0.174 & 0.221 \\
\hline$T_{4,33}$ & 0.131 & 0.215 & 0.175 & 0.220 \\
\hline$T_{4,44}$ & 0.237 & 0.214 & 0.276 & 0.216 \\
\hline$T_{4,55}$ & 0.121 & 0.216 & 0.163 & 0.212 \\
\hline$T_{4,66}$ & 0.145 & 0.225 & 0.156 & 0.219 \\
\hline$\sigma_{x x}$ & 0.314 & 0.058 & 0.315 & 0.059 \\
\hline$\sigma_{x y}$ & - & - & 0.267 & 0.054 \\
\hline$\sigma_{y x}$ & - & - & 0.267 & 0.054 \\
\hline$\sigma_{y y}$ & 0.315 & 0.060 & 0.316 & 0.059 \\
\hline$\sigma_{x \nu_{1}}$ & 0.049 & 0.010 & 0.047 & 0.010 \\
\hline$\sigma_{x \nu_{2}}$ & 0.048 & 0.010 & 0.047 & 0.010 \\
\hline$\sigma_{x \nu_{3}}$ & 0.084 & 0.030 & 0.081 & 0.028 \\
\hline$\sigma_{y \nu_{1}}$ & 0.049 & 0.011 & 0.048 & 0.010 \\
\hline$\sigma_{y \nu_{2}}$ & 0.049 & 0.011 & 0.048 & 0.011 \\
\hline$\sigma_{y \nu_{3}}$ & 0.085 & 0.030 & 0.080 & 0.027 \\
\hline$\sigma_{x \zeta_{1}}$ & 0.047 & 0.010 & 0.044 & 0.009 \\
\hline$\sigma_{x \zeta_{2}}$ & 0.042 & 0.008 & 0.041 & 0.008 \\
\hline$\sigma_{x \zeta_{3}}$ & 0.047 & 0.010 & 0.047 & 0.010 \\
\hline$\sigma_{y \zeta_{1}}$ & 0.047 & 0.010 & 0.043 & 0.009 \\
\hline$\sigma_{y \zeta_{2}}$ & 0.042 & 0.009 & 0.042 & 0.009 \\
\hline$\sigma_{y \zeta_{3}}$ & 0.048 & 0.010 & 0.047 & 0.010 \\
\hline
\end{tabular}


We compare the AR and VAR models of the true values with and without correlated news across time on the basis of marginal likelihoods, which are computed using the procedure described in Chib (1995). Table 7 shows the results. The best model is the $\operatorname{VAR}(2)$ model of the true values of exports and imports with correlations across time in news and noise. As already noted, the better fit of the VAR models is due to the correlation between the shocks of the true values and not to the inclusion of past lags of the other variable in the dynamic equations. In addition, we find that measurement errors should be allowed to be correlated across time, which reflects the sensitivity to new information in a vintage not only for the most recent observation but also for other observations in that vintage.

Table 7: Model comparison

\begin{tabular}{lc} 
Model & Marginal likelihood (ln) \\
\hline AR(2) w/o spillovers & -174.627 \\
AR(2) with spillovers & -167.895 \\
& \\
VAR(2) w/o spillovers & -153.283 \\
VAR(2) with spillovers & -141.061 \\
\hline
\end{tabular}

Note: spillovers are defined here as measurement errors that are correlated across time. 


\section{Conclusion}

This paper proposed a quite general state-space framework to model multivariate data revisions, i.e. revisions occurring in more than one series at a time, allowing correlated true values and news and noise measurement errors. We motivated and illustrated the multivariate framework with Swiss current account data. The Bayesian estimation results demonstrate that our

multivariate data revision framework is feasible. For the Swiss data set, a multivariate approach does pays off: VAR systems for the true values are superior to AR processes due to the correlation between shocks to the true values of imports and exports. In addition, there is a role in the model for measurement errors that are correlated across time. Future research will deal with the impact of correlated measurement errors across vintages. 


\section{Acknowledgements}

This paper was written during visits of the first author to CIRANO and KOF Swiss Economic Institute, and of the second and the fourth author to the research school SOM of the University of Groningen. The hospitality and the support of these institutions, as well as that of CIREQ is gratefully acknowledged. We thank the Swiss National Bank (SNB) for kindly providing us with the data. Jacobs and van Norden would like to thank (without implicating) the late Prof. Arnold Zellner for encouraging them to pursue this topic. We thank Ataman Ozyildirim, Tim Hampton, and participants at the CIRET conference, New York, October 2010, the Workshop on Finance and the Macroeconomy, CAMA, ANU, October 2010, the International Symposium on Forecasting, Prague, June 2011, the 10th Oxmetrics User Conference, Maastricht, September 2011, the 2012 Joint Statistical Meetings, San Diego CA, August 2012, the EABCN Conference: Disaggregating the Business Cycle, Luxembourg, October 2012, the 6th CSDA International Conference on Computational and Financial Econometrics (CFE 2012), Oviedo, Spain, December 2012, the European Meeting of the Econometric Society, Gothenborg, Sweden, August 2013 and the 9th Annual CIRANO-CIREQ Workshop on Data Revision in Macroeconomic Forecasting and Policy, Montréal, October 2013, for helpful comments. 


\section{References}

Aruoba, S. Borağan (2008), "Data revisions are not well behaved", Journal of Money, Credit and Banking, 40, 319-340.

Aruoba, S. Borağan, Francis X. Diebold, Jeremy Nalewaik, Frank Schorfheide, and Dongho Song (2012), "Improving GDP measurement: A forecast combination perspective", in X. Chen and N. Swanson, editors, Causality, Prediction, and Specification Analysis: Recent Advances and Future Directions: Essays in Honor of Halbert L. White Jr, Springer, New York, $1-26$.

Aruoba, S. Borağan, Francis X. Diebold, Jeremy Nalewaik, Frank Schorfheide, and Dongho Song (2013), "Improving GDP measurement: A measurement-error perspective", NBER Working Papers 18954, National Bureau of Economic Research, Inc.

Carter, C. and R. Kohn (1994), "On Gibbs sampling for state space models", Biometrika, 81, 541-553.

Chib, Siddhartha (1995), "Marginal likelihood from the Gibbs output", Journal of the American Statistical Association, 90, 1313-1321.

Clements, Mike and Ana B. Galvão (2012), "Improving real-time estimates of output and inflation gaps with multiple-vintage models", Journal of Business \&6 Economic Statistics [forthcoming]. 
Croushore, Dean (2006), "Forecasting with real-time macroeconomic data", in Graham Elliott, Clive W.J. Granger, and Allan Timmermann, editors, Handbook of Economic Forecasting, North-Holland, Amsterdam.

Croushore, Dean (2011), "Frontiers of real-time analysis", Journal of Economic Literature, 49, 72-100.

Cunningham, Alastair, Jana Eklund, Chris Jeffery, George Kapetanios, and Vincent Labhard (2012), "A state space approach to extracting the signal from uncertain data", Journal of Business 85 Economic Statistics, 30, 173-180.

de Jong, Piet (1987), "Rational economic data revisions", Journal of Business 83 Economic Statistics, 5, 539-548.

Dungey, Mardi, Jan P.A.M. Jacobs, Jing Tian, and Simon van Norden (2013a), "On the correspondence between data revision and trend-cycle decomposition", Applied Economics Letters, 20, 312-315.

Dungey, Mardi, Jan P.A.M. Jacobs, Jing Tian, and Simon van Norden (2013b), "Trend in cycle or cycle in trend? New structural identifications for unobserved components models of U.S. real GDP", Macroeconomic Dynamics [forthcoming].

Durbin, James and Siem-Jan Koopman (2001), Time Series Analysis by State Space Methods, Oxford University Press, Oxford. 
Fixler, Dennis J. and Jeremy J. Nalewaik (2009), "News, noise, and estimates of the true unobserved state of the economy", Mimeo, U.S. Bureau of Economic Analysis, Department of Commerce.

Gelfand, Alan E. and Adrian F. M. Smith (1990), "Sampling-based approaches to calculating marginal densities", Journal of the American Statistical Association, 85, 398-409.

Geman, D. and S. Geman (1984), "Stochastic relaxation, Gibbs distributions and the Bayesian restoration of images", IEEE Transactions on Pattern Analysis and Machine Intelligence, 6, 721-741.

Harvey, A.C. (1989), Forecasting, Structural Time Series Models and the Kalman Filter, Cambridge University Press, Cambridge.

Hecq, Alain and Jan P.A.M. Jacobs (2009), "On the VAR-VECM representation of real time data", Technical report, Maastricht University.

Jacobs, Jan P.A.M. and Jan-Egbert Sturm (2008), "The information content of KOF indicators on Swiss current account data revisions", Journal of Business Cycle Measurement and Analysis, 4, 163-183.

Jacobs, Jan P.A.M and Simon van Norden (2011), "Modeling data revisions: Measurement error and dynamics of "true" values", Journal of Econometrics, 161, 101-109.

Kim, Chang-Jin and Charles R. Nelson (1999), State-Space Models with Regime Switching, The MIT Press, Cambridge MA and London. 
Kishor, N.K. and E.F. Koenig (2012), "VAR estimation and forecasting when data are subject to revision", Journal of Business 8 Economic Statistics, 30, 181-190.

Knetsch, T.A. and H.-E. Reimers (2009), "Dealing with benchmark revisions in real-time data: The case of German production and orders statistics", Oxford Bulletin of Economics and Statistics, 71, 209-235.

Mankiw, N.G., D.E. Runkle, and M.D. Shapiro (1984), "Are preliminary announcements of the money stock rational forecasts?", Journal of Monetary Economics, 14, 15-27.

Mankiw, N.G. and M.D. Shapiro (1986), "News or noise: An analysis of GNP revisions", Survey of Current Business, 66, 20-25.

Mincer, Jacob and Victor Zarnowitz (1969), "The evaluation of economic forecasts", in Jacob Mincer, editor, Economic Forecasts and Expectations: Analyses of Forecasting Behavior and Performance, National Bureau of Economic Research, New York, chapter 1, 3-46.

Patterson, K.D. (2003), "Exploiting information in vintages of time-series data", International Journal of Forecasting, 19, 177-197.

Sargent, T.J. (1989), "Two models of measurements and the investment accelator", The Journal of Political Economy, 97, 251-287.

Schorfheide, Frank and Dongho Song (2012), "Real-time forecasting with a mixed-frequency VAR", Working Paper 701, Federal Reserve Bank of Minneapolis. 
Siklos, P.L. (2008), "What can we learn from comprehensive data revisions for forecasting inflation? Some U.S. evidence", in D. Rapach and M.E. Wohar, editors, Forecasting in the Presence of Structural Breaks and Model Uncertainty, Elsevier, Amsterdam.

Stone, Richard, D. G. Champernowne, and J. E. Meade (1942), "The precision of national income estimates", Review of Economic Studies, 9, 111125.

Swiss National Bank (various issues), Statistische Monatshefte, Swiss National Bank, Zürich.

Zadrozny, Peter A. (2008), "Real-time state-space method for computing filtered estimates of future revisions of U.S. monthly chained CPI", Mimeo, Bureau of Labor Statistics, Washington D.C. 